\title{
Determinants of Knowledge-sharing Networks in Primary Care
}

\author{
Daniele Mascia, PhD \\ Assistant Professor of Organization and Management Theory \\ Università Cattolica del Sacro Cuore and ALTEMS (Graduate School of Health Economics and \\ Management)
}

Francesca Pallotti, PhD

Senior Lecturer in Economic Sociology

University of Greenwich (UK), Centre for Business Network Analysis

\author{
Roberto Dandi, $\mathrm{PhD} *$ \\ Assistant Professor of Management \\ LUISS Guido Carli University \\ ADDRESS: Viale Pola 12, 00198, Roma (Italy) \\ EMAIL: rdandi@luiss.it PHONE: +39 0685222356 FAX: +39 0685225424
}

\section{Acknowledgments}

We gratefully thank Dr. Federica Brunetta (LUISS Guido Carli, Rome) for the help in collecting the data. We thank Professor Franco Fontana (LUISS Guido Carli, Rome), Professor Americo Cicchetti (Università Cattolica del Sacro Cuore, Rome), and Professor Maria Pia Fantini (Università di Bologna, Bologna) for their support and collaboration in this project. We thank the Italian Ministry of Education, Research and University (MIUR) for funding the project. Francesca Pallotti gratefully acknowledges financial support provided by the Swiss National Science Foundation (Grant Number: 146763). This work has been presented and benefited from the helpful comments of participants at the conferences EGOS 2015 Colloquium, SUNBELT 2015 and Academy of Management Annual Meeting 2016. Eventually, we have no conflict of interest to declare.

*Corresponding author 


\begin{abstract}
Background. Around the world, health reforms are increasingly fostering collaboration and integration among primary care physicians with the aim of facilitating knowledge sharing and evidence-informed decision making. Although extant research on this topic is abundant, the evidence and results regarding social and organizational factors affecting the formation of knowledge-sharing networks in this setting are inconclusive.

Purposes. The aim of this article is to explore multiple theoretical mechanisms explaining the formation of knowledge-sharing networks among primary care physicians across relevant clinical areas.

Methodology/Approach. The data are collected from two local health authorities (LHAs) in the Italian National Health Service that are responsible for delivering primary care in two Italian regions. Exponential random graph models are used to test the hypotheses.

Findings. Our findings indicate that knowledge-sharing networks are highly correlated across clinical areas. In addition, knowledge-sharing networks are highly reciprocal and clustered. We also observe that formal models adopted to foster collaboration have remarkably different effects on the formation of knowledge networks, depending upon the diverse knowledge management approaches adopted in the surveyed LHAs.

Practice Implications. Primary care organizations need to develop and implement knowledge management practices in order to help physicians in identifying knowledge domain experts as well as to support connections through formal groupings and incentives.
\end{abstract}

Keywords: knowledge sharing, primary care, social networks, Exponential Random Graph Models, organizational design. 


\section{Determinants of Knowledge-sharing Networks in Primary Care}

\section{Introduction}

Several researchers view knowledge integration among physicians as not only an increasing phenomenon but also as a strategy necessary for addressing several challenges common in healthcare today (Huerta and Dandi, 2014; Keating et al. 2007; Yen-Ju Lin, Lin, and Lin, 2010). First, new medical knowledge continually becomes available, which forces physicians to specialize their knowledge. Second, the spread of evidence-based clinical pathways pushes towards a standardization of medical practices, which often requires non-trivial adaptations to local contexts and individual cases. A third important challenge is the aging of the population, which implies higher incidences of chronic conditions and co-morbidities, which increases the complexity of medical tasks and simultaneously requires the integration of different areas of medical knowledge.

In this context, primary care physicians face even greater challenges because their knowledge cuts across specialties, and they are the first point of contact and access for each need. The knowledge arena of primary care physicians is, therefore, broader and less manageable than that of specialists. In addition, the epidemiological trends significantly affect primary care physicians because, in contrast to specialists, they (are assumed to) always embrace "long-term person- (not disease) focused care" and to focus on comprehensive care for most health needs (Starfield et al., 2005, p. 458). Moreover, the working conditions of primary care physicians, who are often scattered throughout a territory, are not optimal for knowledge sharing and integration (Mascia et al., 2014). Along these lines, policy-makers are becoming increasingly attentive and active in fostering integration in primary care (Fantini et al., 2011; Fattore et al., 2009; YousefiNooraie et al., 2014).

One of the most effective coordination mechanism is represented by physicians' knowledgesharing networks, which involve the establishment of direct relationships aimed at the exchange of advice, opinions, and information between two or more physicians (Mascia et al., 2014; Paul et al., 
2014; Rangachari 2008; Zappa, 2011). As Keating et al. state, “physicians often rely on colleagues for new information to help them interpret the medical literature, and to obtain specific advice about the care of their patients" (2007: 794).

Although prior research is available on the formation of knowledge-sharing networks among physicians, we recognize some limitations in that stream of literature. First, with few exceptions (i.e., Fattore and Salvatore, 2010; Keating et al., 2007; Paul et al., 2014; Yousefi-Nooraie et al., 2014), prior research has relied upon traditional statistical modelling for analyzing such networks, which precludes the possibility of considering important extra-dyadic social tendencies observable in knowledge-sharing networks, such as clustering or the tendency of individuals to share knowledge in groups. Second, most of the prior studies exploring the joint effects of social and organizational factors were conducted in hospital settings. In contrast, little is known about the organizational and social determinants of knowledge networks in primary care settings. Finally, scant knowledge is available about whether knowledge-sharing networks are contingent upon different clinical areas and diverse knowledge governance systems. Recent studies however emphasize that the way clinicians socialize their knowledge and how collective learning processes are enacted rely to a large extent upon governance mechanisms and models adopted for knowledge integration (e.g. Touati, Denis, Roberge \& Brabant, 2015).

This paper contributes to this literature in three main ways. First, we offer a more comprehensive and complete view of knowledge sharing networks in primary care by exploring multiple theoretical mechanisms that may explain the formation of knowledge-sharing networks among physicians. Second, in highlighting the role played by organizational determinants of knowledge networks we explore how different organizational governance mechanisms and models for knowledge integration may trigger the formation of knowledge-sharing networks. Third, we 
highlight the role played by social and organizational determinants of knowledge networks in different clinical areas of primary care.

\section{Theoretical framework}

Physicians largely rely on their colleagues' informal advice when they face complex tasks or when the uncertainty surrounding their patients' medical conditions requires some form of knowledge sharing and exchange (Keating et al., 1998). The most frequent reasons cited by physicians for requesting informal clinical advice include: obtaining an expert's opinion; verifying an opinion and obtaining reassurance; learning from a consultant; obtaining information not readily available; and saving time (Keating et al., 1998). The network perspective is especially useful in studying physicians' informal consultations because knowledge exchange and knowledge sharing are intrinsically relational activities. Many network-based theoretical mechanisms may explain the formation of knowledge-exchange relationships among physicians (Huerta and Dandi, 2014; Paul et al., 2014). A first relevant theory in the context of primary care is balance theory (Monge and Contractor, 2003), which argues that people prefer to build balanced relationships with others in order to avoid discomfort. This theory explains the reciprocity mechanism that is often at the heart of knowledge exchange: actor $i$ connects with or gives something to actor $j$ if $j$ is expected to connect with or give something to $i$ in return. Several healthcare studies have shown that the exchange of clinical knowledge and information among physicians is unlikely to be unilateral (Paul et al., 2014; Yousefi-Nooraie et al., 2014).

Overall, we believe that reciprocal social processes are at play in this context. Therefore, we advance the following hypothesis: 
Hypothesis 1 (HP1): In primary care settings, there is a tendency towards reciprocity in advice networks among physicians.

As acknowledged by recent social network and knowledge-transfer studies (Lomi et al., 2014; Rivera et al., 2010), the presence or absence of advice-seeking relationships between social actors is affected by the presence of a common third party in the network. According to this literature, the very structure of knowledge networks requires the analysis of extra-dyadic network structures involving knowledge-sharing ties established among more than two actors in the network. Burt (1992), for example, suggested that actors may achieve important informational advantages insofar as they act as brokers in the network, bridging other disconnected individuals and groups. This theory emphasizes the brokerage role that third parties play because of the presence of structural holes, understood as a lack of relationships between other actors in the network. According to other research perspectives, a common third party may facilitate knowledge integration and coordination between connected individuals (e.g. Obstfeld, 2005). In the context of knowledge networks, shared third partners represent a relevant source of trust, legitimacy, and reliability for individuals seeking advice (Rivera et al., 2010; Uzzi, 1996) because these third parties have the capacity to reduce "costs and risks inherent in the formation and maintenance of network ties with partners whose quality, capability, and trustworthiness are only imperfectly observable" (Lomi and Pallotti, 2012, p. 202).

The lenses of structural embeddedness appear particularly useful for explaining relevant mechanisms in the formation of relational structures involving three or more individuals: the presence of ties between $i$ and $j$ and between $j$ and $z$ make it more likely that $i$ will turn to $z$ for advice. This is also known as transitive closure. If the presence of ties between $i$ and $j$ and between $j$ and $z$ lead to the formation of a tie from $z$ to $i$, then we observe cyclic closure. Transitive closure 
manifests as a general force toward local hierarchy and, in professional contexts, implies deference among social actors (Papachristos et al., 2013). Recent empirical studies have shown that physicians tend to form transitive triads in multiple health organizations and systems (Paul et al., 2004; Zappa, 2011). In contrast, cyclic closure implies mechanisms of generalized exchange that are unlikely to be observed in knowledge-sharing networks (Lomi et al., 2014). Generalized exchange is typically viewed as unilateral resource giving in which actors' exchange behaviors are permeated by generosity and altruism (Takahashi, 2000). However, knowledge sharing may easily become relationally taxing for the sender and the receiver, whose joint involvement and plain commitment are necessary in advice-seeking behaviors. We may expect that physicians carefully assess all potential partners' abilities to provide relevant and useful knowledge, trying to select their partners according to their perception of the colleagues' expertise. Overall, this prevents the formation of cyclic patterns of connectivity.

Overall, these arguments lead to the following hypotheses:

Hypothesis 2 a (HP2a): In primary care settings, there is a tendency toward transitive closure in advice networks among physicians.

Hypothesis $2 b(H P 2 b)$ : In primary care settings, there is a tendency against cyclic closure in advice networks among physicians.

Social foci theory (Feld, 1981) proposes that individuals sharing the same social focus (e.g. organizational unit, teams etc.) are more likely to interact. One of the most important social foci in organizations is represented by the formal organizational structure, typically functional or divisional units in which individuals are grouped. The organizational literature recognizes the relevance of formal organizational solutions for understanding social networks (McEvily et al., 
2014). However, also knowledge management models and tools adopted to foster knowledge integration likely influence knowledge socialization and learning processes. Touati et al. (2015), for example, document the utilization of different knowledge management approaches in the Quebec health care system. A first approach, termed "mechanistic", relies on evidence-based procedures that circulate and are diffused in organizations to influence clinical practices. According to this view, collective learning is enacted through knowledge circulation and diffusion within systems and organizations. In the second approach called "organic", or laissez-faire, learning is instead fostered by actors' spontaneous interaction and the way they aggregate in professional communities. This approach is bottom up because physicians' interaction and the way they collaborate to form communities of knowledge are considered a viable strategy for knowledge sharing. Implicit in this distinction is that organizational models and tools adopted to facilitate knowledge circulation can vary considerably Despite such differences, the adoption of formal groups (e.g., temporary task forces and primary care units) and other mechanisms of coordination (e.g., implementation of clinical-diagnostic guidelines and clinical pathways, electronic sharing of patient records) have been shown to increase opportunities for physicians to regularly share their knowledge, ideas, and opinions (Armeni et al., 2014; Fattore et al., 2009).. In light of this discussion, we propose the following:

Hypothesis 3 (HP3): In primary care, the propensity of physicians to be involved in advice networks is positively associated with the existence of formal models of coordination.

Studies about information seeking behavior of physicians document that physicians follow the "Principle of Least Effort" when looking for new information (e.g., Gaither et al, 1994; Peay and Peay, 1990). According to this principle, physicians prefer the known to the unknown in their 
information-seeking behaviors. Physicians routinely access and use relevant clinical-knowledge sources to support their medical decisions. Prior research demonstrates, for example, that physicians tend to adopt similar behaviors in the use of medical knowledge regardless of the fact that the clinical problems affecting their patients differ (Elstein, 1999). In a study covering 228 internal medicine and family practice clinicians, Curley et al. (1990) demonstrate that the use of medical knowledge is closely related to the costs associated with knowledge sources and configurations.

In general, costs are high when knowledge is accessed via social relationships (Borgatti and Cross, 2003). In order to reduce uncertainty, optimize effort, and limit coordination costs, primary care physicians tend to rely on the same source of knowledge, i.e., the same colleagues, regardless of the specific pathologies they handle. As long as they rely on the same peers to exchange knowledge, we hypothesize that similar network configurations are likely to be observed in knowledge-sharing networks. More formally, we hypothesize the following:

Hypothesis 4 (HP4): In primary care settings, advice networks among physicians exhibit similar relational patterns across different pathologies.

\section{Methods}

\subsection{Empirical setting}

Since 1978, the Italian National Health Service (I-NHS) has provided primary pediatric care to children through local, community-based pediatricians. In the Italian primary care sector, pediatricians are involved in taking care of children aged 0 to 16 , and they are organized in health districts, which belong to regional Local Health Authorities (LHAs). Districts represent 
organizational subunits of LHAs to which GPs are affiliated and are responsible for coordinating and providing primary care to their reference pool of patients.

Most Italian pediatricians are physically isolated in their own offices, and they are geographically dispersed. One resulting problem is the absence of coordination among pediatricians, which leads to a lack of continuity of care and appropriateness in the use of health services in the NHS. In order to deal with this issue, physicians receive incentives to group together in "associations" or "groups" in which they may share patients, information, and offices, and from which they can more easily coordinate with hospitals (Visca et al., 2013). This organizational solution promotes the creation of local communities of pediatricians in which patients have easier access to doctors and doctors can better take care of children with chronic diseases.

In this paper, we analyze primary care pediatricians belonging to two LHAs in northern Italy. These two settings were selected because of their location in two regions where primary care physicians are encouraged to go beyond their traditional gatekeeper role, assuming a pivotal role in coordinating strategies aimed to deal with chronic and degenerative diseases. LHA1 is characterized by a strong governance system in which planning, execution, and control are strictly enforced. Over time, LHA1 has developed an integrated information system aimed at gathering data about the performance of its primary care physicians in terms of avoidable hospitalizations. LHA1 has also established a formal unit devoted to primary care coordination with the goal of standardizing best practices and spreading the LHA's policies across physicians in the region. One specific policy adopted in this LHA is to foster knowledge exchange within and across physicians groups through monetary incentives. LHA2 has a different story. In this organization, the governance model does not include formal coordination across districts. Moreover, LHA2 does not gather performance data about single primary care physicians. Rather, it relies on payment indicators that almost exclusively take into account the volume of assisted patients. Overall, while 
in LHA1 there is great awareness of the need to integrate healthcare professionals involved in primary care, in LHA2 such awareness is less evident because strategies and knowledge integration mainly rely on pediatricians' affiliation to groups or communities of professionals. Overall, governance systems adopted in LHA1 and LHA2 resemble, respectively, the above mentioned "mechanistic" and "laissez-faire" knowledge management approaches (Touati et al., 2015). Despite these differences, both organizations exhibit comparable levels of effectiveness in the delivery of primary care services, according to the I-NHS's National Outcome Evaluation Program (Programma Nazionale Esiti, 2015).

To collect data in these two organizations, an online survey was administered to all pediatricians belonging to the two focal LHAs in December 2009. The survey, which was inspired by the Knowledge Asset Mapping Exercise in Palazzolo (2005) and structured according to the format proposed by Wasserman and Faust (1994) for network data collection, included questions about respondent attributes (i.e., gender, years of experience, affiliations with formal groups) and advice seeking relationships with other pediatricians in the respective LHA (a roster was used with all of the pediatricians' names listed in the survey). The following question was asked to physicians to collect advice ties data: "Suppose that you are confronted with a clinical problem that is affecting one of your patients, for which you cannot find a solution yourself. To whom of your colleagues would you go to for advice?" Specifically, we collected data on advice-seeking relationships concerning three types of illness: asthma, urinary-tract infections, and gastrointestinal issues. The response rates were 64\% (75 of 117) for LHA1 and 88\% (22 of 25) for LHA2. The overall response rate was $68 \%$.

On the basis of this information, we reconstructed three asymmetric adjacency sociomatrices (Wasserman and Faust, 1994), one for each type of illness, for both LHA1 and LHA2. This gave a total of six adjacency matrices. In each sociomatrix, surveyed physicians are reported in rows and 
columns, such that the interception cells in the matrices indicate the presence (value $=1$ ) or absence (value $=0)$ of an advice tie.

\subsection{Statistical network analysis}

Exponential random graph models (ERGMs), also known as p-star $\left(p^{*}\right)$ models (Lusher et al., 2013), are used here to model the likelihood of observing advice ties between physicians. Thus, the presence of an advice tie is our main dependent variable. The distinctive feature of this modelling framework is that it supports statistical inference of the processes that influence the formation of ties between physicians. ERGMs allow to study network formation by explicitly modeling endogenous factors that may shape the observed network along with exogenous factors such as actor- or dyadic- specific characteristics (Robins et al., 2007; Lusher et al., 2013).

ERGMs can include different types of endogenous network configurations reflecting important social processes, such as reciprocity or clustering that may simultaneously affect the formation of observed global networks. Moreover, ERGMs can incorporate any number of binary, categorical, or continuous actor- or dyadic- specific covariates that may affect exogenously the propensity of physicians to share knowledge by establishing advice ties. Actor covariates can be used to examine whether a given physician's characteristic affects his or her propensity to send and/or receive advice ties from peers (Zappa, 2011). Actor covariates can also be used to examine whether similarities or differences in some individual characteristics involving two actors in a dyad affect the formation of an advice tie between them(Keating et al., 2007).

The ERGM used here has the following general form (Robins et al, 2007):

$$
\operatorname{Pr}(\boldsymbol{X}=\boldsymbol{x})=\left(\frac{1}{k}\right) \exp \left[\sum_{A} \eta_{A} Z_{A}(x)\right]
$$


where $\operatorname{Pr}(\boldsymbol{X}=\boldsymbol{x})$ is the probability of observing the network that has been measured; $A$ represents a configuration of network ties included in the model, such as arc, reciprocity, transitive closure; $\sum_{\mathrm{A}}$ is the summation over all different configurations in the model; $\eta_{A}$ is the unknown parameter to be estimated corresponding to configuration $A$ and determining the effect of the configuration; $Z_{A}(x)$ is the network statistic corresponding to configuration A and is simply a count of the presence of configuration A in the observed network; $k$ is a normalizing quantity included to ensure that [1] is a proper probability distribution. Equation (1) can also be modified to include additional covariate information such as actor or dyadic-specific covariates. Actor covariates may enter the model specification as actor-relation main effects (i.e., sender and receiver effects) as well as actorrelation homophily/difference effects (Lusher et al., 2013). All dyadic covariates included in (1) enter the model as main Covariate Arc effect, expressing the effect of the covariate on the presence of a network tie (see Table 1). Because ERG are models for network ties, the unit of analysis is the dyad. Accordingly, the number of observations for LHA1 are 5,550 (75 x 74) for each of the network analyzed, and $462(22 \times 21)$ for LHA2.

\subsection{Variables and Measures}

\subsubsection{Endogenous effects}

Endogenous effects account for structural processes, or tendencies, within a network. To test our research hypotheses, we include specific parameters in the model that capture salient structural features of the observed networks, such as reciprocity (HP1), or the tendency of physician A to be sought for advice by physician B who had been already sought for advice by physician A; transitivity (HP2a), or path closure: if physician A seeks advice from B, and B from C, there will be a tendency of A to overcome the indirect relation and seek advice directly from C; and cyclic 
closure (HP2b): physician A asks B for advice, who asks C, who asks A. This effect may indicate local generalized exchange.

We also control for the density of the network $(A r c)$ and for differences in the relational activity of senders and receivers as revealed by differences in the: (i) propensity of physicians to be asked for advice by many others (simple popularity and popularity spread); (vi) propensity of physicians to turn to many others for advice (simple activity and activity spread,), and (vii) tendency of incoming and outgoing ties to co-occur (simple connectivity). Popularity and activity spread parameters are typically used to capture the tendency of network centralization in the inand out-degree distributions. The simple connectivity parameter captures a tendency for the formation of non-closure structures where an actor connects others not directly connected; in our study, the tendency of physicians $\mathrm{A}$ and $\mathrm{C}$ to exchange advice through physician $\mathrm{B}$, who would act as a broker.

\subsubsection{Exogenous covariates}

To test Hypothesis 3 (HP3), we include in the model a number of covariates capturing the tendency of advice ties to organize around different types of formal coordination models. The first is a dyadic covariate that captures past common affiliation of physicians to taskforces created to develop jointly clinical pathways for specific pathologies. The second is a binary covariate (Association) taking the value of 1 if a physician belongs to an association, and 0 otherwise. This covariate enters the model as matches (see Table 1 for explanation). To capture membership of physicians to the same association, we also include a dyadic covariate reporting in the cells the value of 1 if physicians $i$ and $j$ jointly participate to the same association, and 0 otherwise. Associations are examples of formal groupings to which physicians affiliate themselves on a voluntary basis (Visca et al., 2013). The fourth covariate (District) captures membership of physicians to the health 
districts in which the two LHAs are partitioned. This is a categorical variable ranging from 1 to 6 for physicians in LHA1 and from 1 to 2 in LHA2. This covariate enters the model as matches (see Table 1).

We also control for a variety of sources of heterogeneity that may affect the presence of advice ties among physicians. We include Experience to control for the effect of years of tenure. Other conditions being equal, we expect experienced physicians to be less likely to send advice ties and be more likely to: i) receive advice-seeking ties; ii) being sought by many others for advice, and iii) exchange advice with less experienced physicians. Accordingly, this covariate enters the model as sender, receiver, popularity, and difference effects, respectively (see Table 1). We include Gender to test whether physicians of the same gender are more likely to exchange advice ties. Gender is a binary variable taking the value of 1 for females and 0 otherwise. This covariate enters the model as matches (see Table 1). We also control for geographical distance (in kilometers) between each pair of physicians to account for the possibility that knowledge sharing is more likely between physicians that are physically closer to each other (Keating et al., 2007; Paul et al., 2014). The dyadic covariates "same association", "taskforce" and "geographical distance" enter the model as main Covariate Arc effects. Table 1 summarizes the definitions of the endogenous and exogenous effects included in the empirical model.

Table 1 around here

\section{Results}

Table 2 reports basic characteristics of the sampled physicians in the two LHAs. Most of the physicians who responded to the survey are female (77.3\% in LHA1, 54.5\% in LHA2), and most 
(70.7\% in LHA1 and $77.3 \%$ in LHA2) report to be affiliated to professional associations. The physicians' average experience is quite similar in the two LHAs (21.6 years in LHA1, and 19.9 years in LHA2), whereas the average geographical distance between them is moderately different (20.3 kilometers in LHA1 and 16.5 kilometers in LHA2). The number of physicians participating in taskforces is lower in LHA1 than in LHA2.

Table 3 provides basic descriptive statistics and correlation coefficients between networks within each LHA. Correlation coefficients are high and positive in both LHAs. This may suggest that the structure of the advice networks is similar, regardless of the pathology being considered. Hence, we expect the structural effects corresponding to the various network configurations described earlier (and reported in Table 1) to be similar across networks within the same LHA.

Tables 2 and 3 around here

The results of the ERGMs for the six networks are shown in Table 4. Parameter estimation is conducted using Markov Chain Monte Carlo Maximum Likelihood simulation-based techniques (Robins et al., 2007). ERGM estimation is done using the PNet program (Wang, Robins and Pattison, 2006). When the parameter estimate is greater than two times (in absolute value) the standard error, the parameter is regarded as significant and is denoted by an asterisk in the table. A large positive (negative) parameter suggests that the corresponding configuration is observed in the network more (less) frequently than what would be expected by chance only, conditional on the presence of other configurations in the model. The results of the GOF diagnostic procedure suggest that the fitted models reproduce with accuracy salient structural features of our observed data. Results of the GOF analysis are available upon request. 
Results in Table 4 show that across the six models advice ties are unlikely (Arc) unless they are reciprocated (positive and significant Reciprocity). This provides support to HP1. A positive coefficient for Path-Closure, together with a negative coefficient for Simple connectivity, suggests a tendency of advice ties to organize around clusters. This result is confirmed for all networks with the exception of the network of urinary traits infections in LHA2, for which there seems to be a tendency toward brokerage. This overall provides some support to HP2a. The parameter estimate for Cyclic-Closure is negative across all networks (but not significant for the urinary network in LHA2), suggesting a general strong tendency against generalized exchange. In other words, physicians are unlikely to exchange advice ties in cyclic structures. This overall provides support to HP2b. With the only exception of the advice network of asthma in LHA2, for which there is a positive tendency toward centralization in the in-degree distribution (simple popularity), the coefficients accounting for differences in popularity and activity among physicians are not significant, or negative, across the other models. This result suggests that clusters in these networks are not driven by particularly popular or active physicians; rather, they are driven by groups of overlapping (transitive) triangles.

The purely structural effects overall suggest that physicians tend to reciprocate advice ties, and that there is considerable clustering in the way advice ties organize themselves. A comparison of the purely structural effects across the various models also suggest that the underlying social processes that these effects unveil are actually very similar in both LHAs - this finding being also corroborated by the (significantly positive) correlation coefficients in Table 3 . The network of urinary traits infections in LHA2 stands out as slightly different from the others: there is no 
tendency toward clustering and there is a tendency against brokerage, thus indicating that extradyadic structures are unlikely to be observed in this network.

The effects of affiliation to formal settings vary between the two LHAs. In LHA1 results show that membership to associations does not increase the likelihood of advice ties to be created among physicians (negative and significant parameter for Association); when physicians belong to the same association, however, they will be more likely to seek advice from each other (positive and significant parameter for same association). In LHA1, on the other hand, it is participation to health districts and, to a lesser extent, to taskforces that makes advice ties among physicians more likely to occur. This overall provides supports to HP3, and shows that major differences can be found between the two LHAs in terms of effectiveness of different formal models in enhancing coordination and knowledge sharing among physicians.

In terms of physician-specific characteristics, results show that neither gender nor experience play a significant role. The results suggest, however, that there is a general tendency toward homophily with respect to tenure: physicians are more likely to share advice with similarly experienced physicians (negative parameter for Experience (difference)). Finally, in line with previous studies (Paul et al., 2014; Yousefi-Nooraie et al., 2014) results show that physical distance has a negative effect on advice ties formation in both LHAs and across all pathologies.

\section{Discussion}

This paper contributes to existing literature on physician networks by exploring the formation of knowledge-exchange ties in the context of primary care. Our results show that primary care physicians are more likely to ask a colleague for clinical advice when: (i) that colleague is also asking the focal physician for advice (HP1: reciprocity); (ii) that colleague is being asked for advice by someone from whom the focal physician is also requesting advice (HP2a and HP2b: non- 
cyclical clustering); (iii) that colleague belongs to the same organizational model (HP3); (iv) that colleague is physically proximate, and (v) the two colleagues are similar with respect to years of experience.

The strong and positive correlation among advice networks across clinical areas may suggest that physicians tend to rely on the same colleagues for all of their knowledge needs. This information-seeking strategy follows the principle of least efforts because exploiting existing trusted relationships is less costly than developing new ones (HP4). While these relational patterns may be beneficial because they reduce resistance and provide comfort in collaborating with others, they might also reduce the likelihood that valuable information will be diffused. Physicians who only access the same advisors may be less exposed to other colleagues, thus reducing the likelihood that they will access novel information.

Our results also suggest that the two LHAs rely on different sources for advice relationships depending on the characteristics of their organizational contexts and knowledge management approaches. In LHA1, where the governance model of primary care relies upon formal coordination mechanisms, it is membership to health districts that explains the formation of advice ties among physicians. In contrast, in LHA2, where the knowledge management model resembles the laissezfaire approach, the creation of informal advice networks relies more on participation in professional associations to which physicians affiliate spontaneously. In particular, our results suggest that it is not the mere participation to informal groups (e.g., associations, taskforces) that fosters communication and knowledge sharing. Rather, it is membership to the same group that plays a role for the creation of advice ties. This finding seems to suggest that these informal groups both facilitate sharing of knowledge within, as well as prevent it across group boundaries. This result is not context-specific and it has been found elsewhere (Lomi et al., 2014). 
In conclusion, if we view primary care networks as an intermediate form of organization between "hierarchy" and "markets" (Powell, 1990), we may view LHA1 as closer to the hierarchy model and LHA2 as closer to the market model. Neither are hierarchies because transactions (i.e., advice relationships) are not superimposed by the LHA managers, although they are supported by the LHAs to some extent. They are not markets because transactions are not volatile and they are based on trust. However, LHA1 governs through formalized structures and processes, while LHA2 uses a more laissez faire, informal management style.

\section{Practice Implications}

Policymakers and health care administrators in many health systems are increasingly asked to implement interventions aimed at increasing coordination and knowledge integration in primary care. In the US health system, for example, recently enacted health reform legislation has explicitly foreseen the adoption of actions and tools to strengthen the coordination and quality of care, such as the Accountable Care Organizations (ACOs). ACOs are defined as "provider-led organizations with a strong base of primary care that are collectively accountable for quality and total per capita costs across the full continuum of care for a population of patients", and in which payments are linked to quality improvements and innovative performance measurement systems are adopted to support such improvement (McClellan et al., 2010: 983). Our findings have important implications for the creation and maintenance of advice networks in primary care settings. Primary care managers may want to implement network-development interventions (Valente, 2010) aimed at creating new opportunities for knowledge exchange, such as new taskforces for the development of clinical pathways, training programs, incentives for knowledge transfer among associations, periodical plenary meetings of pediatricians, systems supporting expertise recognition and expertise access among pediatricians, and monitoring systems for the assessment of knowledge- 
exchange initiatives. While all these interventions can be, at least in principle, equally beneficial to sustain knowledge exchange, our results show that their effect is contingent upon a number of organizational characteristics and idiosyncrasies. Knowledge-sharing ties can be facilitated through the implementation of a wide range of formal models. Policymakers and managers may want to consider the knowledge governance approach in health organizations, i.e. "mechanistic" versus "laissez-faire" models, before adopting coordination models and incentives aimed at fostering knowledge sharing among physicians. Our findings also suggest that institutional arrangements, such as for example organizational districts, can be replaced or complemented by less formalized coordination initiatives, such as associations, that sustain the diffusion of knowledge and skills among their participants. Health care managers and administrators should therefore encourage participation to these initiatives, through monetary and non-monetary incentives. Specific attention should also be paid to incentives that encourage knowledge transfer from more experienced to less experienced physicians, as well as knowledge sharing across boundaries defined by formal and informal groups.

\section{Limitations and Future Research Avenues}

Our findings must be interpreted in light of a number of limitations, each of which suggests directions for future research. First, we could not include performance data in the analysis to assess the effectiveness of the different governance models. The analysis of whether and how governance models and network structures may affect a number of outcome variables surely deserves attention in future research. A second major limitation of our research is that the present study is crosssectional. As such, we were not in a position to clarify the impact of the variables on the evolution of advice relationships over time. Future studies should focus on factors affecting the evolution and change of knowledge-sharing networks in primary care settings. Third, our analyses were 
focused on just two Italian LHAs, which limits the generalizability of our findings. While our empirical setting is characterized by a number of institutional idiosyncrasies, we believe the problem we have addressed is general and surely deserves additional attention in future research. Replications of our study in other health systems may establish the generality of our models and results.

Despite these limitations, our paper contributes to the debate on physician networks. It sheds new light on the conditions that explain the formation of primary care networks by using an innovative network-modelling technique and testing the effects of multiple theoretical mechanisms on the formation of knowledge-sharing networks.

\section{References}

Armeni, P., Compagni, A., Longo, F. (2014). Multiprofessional Primary Care Units: What Affects the Clinical Performance of Italian General Practitioners? Medical Care Research \& Review, 71(4), 315-336.

Borgatti, S.P., Cross, R. (2003). A relational view of information seeking and learning in social networks. Management Science, 49(4), 432-445.

Burt, R.S. (1992). Structural Holes: The Social Structure of Competition. Harvard University Press.

Curley, S.P., Connelly, D.P., Rich, E.C. (1990). Physicians' Use of Medical Knowledge Resources. Medical Decision Making, 10(4), 231-241.

Elstein, A.S. (1999). Heuristics and Biases: Selective Errors in Clinical Reasoning. Academic Medicine, 74, 791-794. 
Fantini, M.P., Compagni, A., Rucci, P., Mimmi, S., Longo, F. (2011). General practitioners adherence to evidence-based guidelines: a multilevel analysis. Health Care Management Review, $74,225-230$.

Fattore, G., Salvatore, D. (2010). Network organizations of general practitioners: antecedents of formation and consequence of participation. BMC Health Services Research, 10, 118.

Fattore, G., Frosini, F., Salvatore, D., et al. (2009). Social network analysis in primary care: the impact of interactions on prescribing behaviour. Health Policy, 92, 141-148.

Feld, S.L. (1981). The Focused Organization of Social Ties. American Journal of Sociology, $86,1015-1035$.

Gaither, C. A., Bagozzi, R. P., Kirking, D. M., and Ascione, F. J. (1994). Factors related to physicians' attitudes and beliefs toward drug information sources. Drug Information Journal, 28 (3), 817-827.

Huerta, T.R. and Dandi, R. (2014). Social Network Analysis and the Integration of Care: Theory and Method. In Mick, S.S., Shay, P.D. (Eds.), Advances in Health Care Organization Theory, 2nd Edition, (pp. 229-258). San Francisco. Jossey-Bass Inc.

Keating, N.L., Ayanian, J.Z., Cleary, P.D., Marsden, P.V. (2007). Factors affecting influential discussions among physicians: a social network analysis of a primary care practice. Journal of General Internal Medicine, 22, 794-798.

Krackhardt, D. (1987). Predicting with networks: Nonparametric multiple regression analysis of dyadic data. Social Networks, 10, 359-381.

Lomi, A., Lusher, D., Pattison, P.E., Robins, G. (2014). The Focused Organization of Advice Relations: A Study in Boundary Crossing. Organization Science, 25(2), 438-457.

Lomi, A., Pallotti, F. (2012). Relational collaboration among spatial multipoint competitors. Social Networks, 34, 101-111. 
Lusher, D., Koskinen, J., Robins, G. (2013). Exponential Random Graph Models for Social Networks: Theory, Methods, and Applications. New York: Cambridge University Press.

Mascia, D., Dandi, R., Di Vincenzo, F. (2014). Professional Networks and EBM Use: A Study of Inter-physician interaction across levels of care. Health Policy, 118(1), 24-36.

McClellan, M., McKethan, A.N., Lewis, J.L., Roski, J., Fisher, E.S. (2010). A National Strategy To Put Accountable Care Into Practice. Health Affairs, 29(5): 982-990.

McEvily, W., Soda, G., Tortoriello, M. (2014). More formally: Rediscovering the missing link between formal organization and informal social structure. Academy of Management Annals, 8, 299-345.

Monge, P.R., Contractor, N.S. (2003). Theories of Communication Networks. New York: Oxford University Press.

Obstfeld, D. (2005). Social networks, the tertius iungens orientation, and involvement in innovation. Administrative Science Quarterly, 50, 100-130.

Palazzolo, E. T. (2005). Organizing for information retrieval in transactive memory systems. Communication Research, 32, 726-761.

Papachristos, A.V., Hureau, D.M., Braga, A.A. (2013). The Corner and the Crew: The Influence of Geography and Social Networks on Gang Violence. American Sociological Review, 78(3), 417-447.

Paul, S., Keating N.L., Landon, B.E., O’Malley, A.J. (2014). Results from using a new dyadic-dependence model to analyze sociocentric physician networks. Social Science \& Medicine, $117,67-75$.

Peay, M. Y., \& Peay, E. R. (1990). Patterns of preference for information sources in the adoption of new drugs by specialists. Social Science \& Medicine, 31 (4), 467476. 
Programma Nazionale Esiti (2015). Sintesi per struttura / ASL. Retrieved January 1, 2016, from http://95.110.213.190/PNEed14/index.php.

Powell, W.W. (1990). Neither Market nor Hierarchy: Network Forms of Organization. In Staw, B.M., Cummings, L.L. (Eds.), Research in Organizational Behavior, (pp. 295 - 336). Greenwich, CT: JAI Press.

Rangachari, P. (2008). Knowledge sharing networks related to hospital quality measurement and reporting. Health Care Management Review, 33(3), 253-263.

Rivera, M.T., Soderstrom, S.B., Uzzi, B. (2010). Dynamics of dyads in social networks: Assortative, relational, and proximity mechanisms. Annual Review of Sociology, 36, 91-115.

Robins, G., Pattison, P., Wang, P. (2009). Closure, connectivity, and degree distributions: Exponential Random Graph ( $\left.\mathrm{p}^{*}\right)$ Models for directed social networks. Social Networks, 31, 105117.

Robins, G., Pattison, P., Kalish, Y., Lusher, D. (2007). An introduction to exponential random graph ( $\left.\mathrm{p}^{*}\right)$ models for social networks. Social Networks, 29, 173-191.

Starfield, B., Shi, L., Macinko, J. (2005). Contribution of primary care to health systems and health. Milbank Quarterly, 83, 457-502

Takahashi, N. (2000). The Emergence of Generalized Exchange. American Journal of Sociology, 105(4), 1105-1134.

Touati, N., Denis, J-L., Roberge, D., Brabant, B. (2015). Learning in Health Care Organizations and Systems: An Alternative Approach to Knowledge Management. Administration \& Society, 47(7), 767-801.

Valente, T.W. (2010). Social Networks and Health: Models, Methods, and Applications. Oxford: Oxford University Press. 
Visca, M., Donatini, A., Gini, R., Federicom B., Damiani, G., Francesconi P, et al. (2013). Group versus single handed primary care: a performance evaluation of the care delivered to chronic patients by Italian GPs. Health Policy, 113 (1-2), 188-198.

Wang, P., Robins, G., Pattison, P. (2006). PNET: Program for the simulation and estimation of $\mathrm{p} *$ exponential random graph models. Melbourne, Australia: University of Melbourne. Retrieved from http://www.sna.unimelb.edu.au/pnet/ pnet.html

Wasserman, S.S., Faust, K. (1994). Social Network Analysis: Methods and Applications. New York: Cambridge University Press.

Yen-Ju Lin, B.; Lin, Y-K.; Lin, C.-C. (2010). Partnership effectiveness in primary community care networks: A national empirical analysis of partners' coordination infrastructure designs. Health Care Management Review, 35(3), 224-234.

Yousefi-Nooraie, R., Dobbins, M., Marin, A. (2014). Social and organizational factors affecting implementation of evidence-informed practice in a public health department in Ontario: a network modelling approach. Implementation Science, 9, 29.

Zappa, P. (2011). The network structure of knowledge sharing among physicians. Quality and Quantity, 45, 1109-1126. 


\section{TABLES}

\section{Table 1. Configurations included in the analysis}

\begin{tabular}{|c|c|c|}
\hline STATISTICS & $\begin{array}{c}\text { NETWORK } \\
\text { CONFIGURATION }\end{array}$ & INTERPRETATION \\
\hline Density (Arc) & & Tendency to form advice ties \\
\hline Reciprocity & & Tendency to reciprocate advice ties \\
\hline Simple Activity & & Tendency to send non-exclusive advice ties \\
\hline $\begin{array}{l}\text { Simple } \\
\text { Popularity }\end{array}$ & & Tendency to receive non-exclusive advice ties \\
\hline $\begin{array}{l}\text { Simple } \\
\text { Connectivity }\end{array}$ & & Tendency of incoming and outgoing advice ties to be correlated \\
\hline $\begin{array}{l}\text { Popularity } \\
\text { Spread }\end{array}$ & & Tendency to receive multiple advice ties \\
\hline Activity Spread & & Tendency to send multiple advice ties \\
\hline Path Closure & & Tendency of advice ties to cluster into transitive triads \\
\hline Cyclic Closure & & Tendency of advice ties to cluster into cyclic triads \\
\hline Statistics & $\begin{array}{c}\text { CONFIGURATION } \\
\text { OF EXOGENOUS } \\
\text { VARIABLES }\end{array}$ & INTERPRETATION \\
\hline Sender & & $\begin{array}{l}\text { Tendency of physicians with (higher) attribute values to initiate advice } \\
\text { ties }\end{array}$ \\
\hline Receiver & & $\begin{array}{l}\text { Tendency of physicians with (higher) attribute values to receive advice } \\
\text { ties }\end{array}$ \\
\hline $\begin{array}{l}\text { Homophily } \\
\text { (Difference) }\end{array}$ & & $\begin{array}{l}\text { Tendency of physicians to select other physicians with similar attribute } \\
\text { values for advice }\end{array}$ \\
\hline $\begin{array}{l}\text { Attribute } \\
\text { popularity }\end{array}$ & & $\begin{array}{l}\text { Tendency of physicians with (higher) attribute values to receive advice } \\
\text { ties }\end{array}$ \\
\hline $\begin{array}{l}\text { Matched } \\
\text { category }\end{array}$ & & $\begin{array}{l}\text { Tendency of physicians with a binary or categorical attribute to select } \\
\text { other physicians with the same attribute for advice }\end{array}$ \\
\hline Covariate arc & & $\begin{array}{l}\text { Tendency of a dyadic covariate to affect the presence of an advice tie } \\
\text { between physicians }\end{array}$ \\
\hline
\end{tabular}


Determinants of Knowledge-sharing Networks in Primary Care

Table 2. Characteristics of sampled physicians

\begin{tabular}{|c|c|c|}
\hline & LHA1 $(n=75)$ & LHA2 $(n=22)$ \\
\hline \multicolumn{3}{|l|}{ Gender, $N$ Physicians (\%) } \\
\hline Male & $17(22.7)$ & $10(45.5)$ \\
\hline Female & $58(77.3)$ & $12(54.5)$ \\
\hline Experience, Year, Mean \pm SD (range) & $21.6 \pm 7.1(6-34)$ & $19.9 \pm 7.3(8-35)$ \\
\hline \multicolumn{3}{|c|}{ Association Membership, $N$ Physicians (\%) } \\
\hline Solo practice & $22(29.3)$ & $5(22.7)$ \\
\hline Association & $53(70.7)$ & $17(77.3)$ \\
\hline \multicolumn{3}{|l|}{ District Membership, $N$ Physicians (\%) } \\
\hline District \#1 & $32(42.7)$ & $9(40.9)$ \\
\hline District \#2 & $14(18.7)$ & $13(59.1)$ \\
\hline District \#3 & $17(22.7)$ & - \\
\hline District \#4 & $11(14.7)$ & - \\
\hline District \#5 & $9(12.0)$ & - \\
\hline District \#6 & $13(17.3)$ & - \\
\hline Distance, $\mathrm{Km}$, Mean \pm SD (range) & $20.3 \pm 17.1(0-99)$ & $16.5 \pm 9.3(0-41)$ \\
\hline \multicolumn{3}{|l|}{$\begin{array}{l}\text { Task force common affiliation, number of } \\
\text { physicians }{ }^{\text {a }}\end{array}$} \\
\hline Task Force \#1 & 3 & 12 \\
\hline Task Force \#2 & 7 & 12 \\
\hline Task Force \#3 & 2 & 12 \\
\hline Task Force \#4 & 3 & 1 \\
\hline Task Force \#5 & - & 2 \\
\hline
\end{tabular}

${ }^{a}$ Physicians may participate in more than one taskforce 
Determinants of Knowledge-sharing Networks in Primary Care

Table 3. Descriptive statistics and Pearson correlation coefficients

\section{LHA1}

\begin{tabular}{llcccccc}
\hline & Variable & $\begin{array}{c}\text { Mean } \\
\text { (Network Density) }\end{array}$ & st.dev. & Min. & Max. & 1 & 2 \\
\hline 1 & Net_asthma & 0.02 & 0.14 & 0 & 1 & - & \\
2 & Net_gastro & 0.02 & 0.13 & 0 & 1 & $0.81^{* *}$ & - \\
3 & Net_urinary & 0.02 & 0.13 & 0 & 1 & $0.80^{* *}$ & $0.87^{* *}$ \\
\hline
\end{tabular}

\section{LHA2}

\begin{tabular}{llcccccc}
\hline \multicolumn{1}{l}{ Variable } & $\begin{array}{c}\text { Mean } \\
\text { (Network Density) }\end{array}$ & st.dev. & Min. & Max. & 1 & 2 \\
\hline 1 & Net_asthma & 0.15 & 0.36 & 0 & 1 & - & \\
2 & Net_gastro & 0.14 & 0.34 & 0 & 1 & $0.83^{* *}$ & - \\
3 & Net_urinary & 0.14 & 0.34 & 0 & 1 & $0.82^{* *}$ & $0.93^{* *}$ \\
& & & & & & \\
\hline
\end{tabular}

Note: $N=5,550$ for LHA1 and $N=462$ for LHA2; Correlation coefficients are computed by using the Quadratic Assignment Procedure (QAP), which computes correlation between entries of two squared matrices while not assuming the independence of observations (Krackhardt, 1987). Significance level, $* *=p<0.01$. Number of permutations: 10,000 . 
Determinants of Knowledge-sharing Networks in Primary Care

Table 4. ERGM parameter estimates (standard errors in parentheses)

\begin{tabular}{|c|c|c|c|c|c|c|}
\hline & \multicolumn{3}{|c|}{ LHA1 $(\mathrm{N}=5,550)$} & \multicolumn{3}{|c|}{ LHA2 (N=462) } \\
\hline & ASTHMA & GASTRO & $\begin{array}{l}\text { URINARY } \\
\text { TRACT } \\
\end{array}$ & ASTHMA & GASTRO & $\begin{array}{c}\text { URINARY } \\
\text { TRACT }\end{array}$ \\
\hline \multicolumn{7}{|l|}{ Endogenous effects } \\
\hline Arc & $\begin{array}{c}-3.0928 * \\
(0.8403)\end{array}$ & $\begin{array}{c}-3.6459 * \\
(0.8590)\end{array}$ & $\begin{array}{c}-4.0944^{*} \\
(0.8413)\end{array}$ & $\begin{array}{c}0.2379 \\
(1.5557)\end{array}$ & $\begin{array}{c}1.2920 \\
(1.8889)\end{array}$ & $\begin{array}{c}2.6762 \\
(2.2391)\end{array}$ \\
\hline Reciprocity & $\begin{array}{l}3.8661 * \\
(0.4479)\end{array}$ & $\begin{array}{l}3.9083 * \\
(0.5171)\end{array}$ & $\begin{array}{l}4.5052 * \\
(0.5198)\end{array}$ & $\begin{array}{l}2.5006 * \\
(1.0192)\end{array}$ & $\begin{array}{l}3.1712 * \\
(0.9513)\end{array}$ & $\begin{array}{l}1.8747 * \\
(0.9314)\end{array}$ \\
\hline Simple Popularity & $\begin{array}{l}-0.3890 \\
(0.6253)\end{array}$ & $\begin{array}{l}-0.4041 \\
(0.7482)\end{array}$ & $\begin{array}{l}-0.2570 \\
(0.8353)\end{array}$ & $\begin{array}{l}0.2843 * \\
(0.1066)\end{array}$ & $\begin{array}{c}0.3326 \\
(0.2053)\end{array}$ & $\begin{array}{c}-0.1292 \\
(1.2537)\end{array}$ \\
\hline Simple Activity & $\begin{array}{c}-0.4178 \\
(0.4333)\end{array}$ & $\begin{array}{c}-0.6368 \\
(0.4588)\end{array}$ & $\begin{array}{l}-0.5726 \\
(0.4415)\end{array}$ & $\begin{array}{c}-0.0094 \\
(0.2229)\end{array}$ & $\begin{array}{l}-0.1858 \\
(0.3887)\end{array}$ & $\begin{array}{c}0.2150 \\
(0.1459)\end{array}$ \\
\hline Simple Connectivity & $\begin{array}{c}-0.4214 * \\
(0.1126)\end{array}$ & $\begin{array}{c}-0.4379 * \\
(0.1230)\end{array}$ & $\begin{array}{c}-0.5402 * \\
(0.1311)\end{array}$ & $\begin{array}{l}-0.1610 \\
(0.1062)\end{array}$ & $\begin{array}{c}-0.1142 \\
(0.1977)\end{array}$ & $\begin{array}{c}-0.4404 * \\
(0.1934)\end{array}$ \\
\hline Popularity Spread & $\begin{array}{c}0.4186 \\
(0.7404)\end{array}$ & $\begin{array}{c}0.5025 \\
(0.8679)\end{array}$ & $\begin{array}{c}0.9876 \\
(0.9692)\end{array}$ & $\begin{array}{c}-1.6023 * \\
(0.6595)\end{array}$ & $\begin{array}{c}-2.9199 * \\
(1.1324)\end{array}$ & $\begin{array}{c}-1.9832 \\
(1.8782)\end{array}$ \\
\hline Activity Spread & $\begin{array}{c}0.8757 \\
(0.7657)\end{array}$ & $\begin{array}{c}1.3873 \\
(0.8171)\end{array}$ & $\begin{array}{c}1.5759 \\
(0.7881)\end{array}$ & $\begin{array}{c}0.5542 \\
(0.7917)\end{array}$ & $\begin{array}{c}1.3754 \\
(1.0697)\end{array}$ & $\begin{array}{c}0.8659 \\
(0.6869)\end{array}$ \\
\hline Path Closure & $\begin{array}{l}1.4588 * \\
(0.2610)\end{array}$ & $\begin{array}{l}1.6479 * \\
(0.2537)\end{array}$ & $\begin{array}{l}1.4445 * \\
(0.2917)\end{array}$ & $\begin{array}{l}1.3310 * \\
(0.3200)\end{array}$ & $\begin{array}{l}1.0680 * \\
(0.3828)\end{array}$ & $\begin{array}{c}0.3559 \\
(0.3650)\end{array}$ \\
\hline Cyclic Closure & $\begin{array}{c}-0.6975 * \\
(0.2791)\end{array}$ & $\begin{array}{c}-0.9474 * \\
(0.2776)\end{array}$ & $\begin{array}{c}-0.8170 * \\
(0.3012)\end{array}$ & $\begin{array}{c}-0.7929 * \\
(0.3381)\end{array}$ & $\begin{array}{c}-0.5508 * \\
(0.3689)\end{array}$ & $\begin{array}{l}-0.4515 \\
(0.3829)\end{array}$ \\
\hline \multicolumn{7}{|c|}{$\begin{array}{l}\text { Exogenous (nodal and } \\
\text { dyadic) effect }\end{array}$} \\
\hline $\begin{array}{l}\text { Gender } \\
\text { (matches) }\end{array}$ & $\begin{array}{l}-0.1913 \\
(0.2194)\end{array}$ & $\begin{array}{l}-0.2176 \\
(0.2411)\end{array}$ & $\begin{array}{l}-0.0744 \\
(0.2267)\end{array}$ & $\begin{array}{c}0.3027 \\
(0.4997)\end{array}$ & $\begin{array}{c}0.3571 \\
(0.4895)\end{array}$ & $\begin{array}{c}0.2849 \\
(0.5379)\end{array}$ \\
\hline $\begin{array}{l}\text { Association } \\
\text { (matches) }\end{array}$ & $\begin{array}{c}0.2056 \\
(0.1977)\end{array}$ & $\begin{array}{c}0.2434 \\
(0.2114)\end{array}$ & $\begin{array}{l}-0.1941 \\
(0.2002)\end{array}$ & $\begin{array}{l}-0.5960 * \\
(0.2903)\end{array}$ & $\begin{array}{r}-1.0636 * \\
(0.5064)\end{array}$ & $\begin{array}{l}-1.5950 * \\
(0.6625)\end{array}$ \\
\hline $\begin{array}{l}\text { Experience } \\
\text { (sender) }\end{array}$ & $\begin{array}{l}-0.0133 \\
(0.0175)\end{array}$ & $\begin{array}{l}-0.0267 \\
(0.0164)\end{array}$ & $\begin{array}{l}-0.0405 * \\
(0.0192)\end{array}$ & $\begin{array}{l}-0.0202 \\
(0.0222)\end{array}$ & $\begin{array}{l}-0.0285 \\
(0.0219)\end{array}$ & $\begin{array}{l}-0.0268 \\
(0.0207)\end{array}$ \\
\hline $\begin{array}{l}\text { Experience } \\
\text { (receiver) }\end{array}$ & $\begin{array}{l}-0.0167 \\
(0.0302)\end{array}$ & $\begin{array}{l}-0.0110 \\
(0.0290)\end{array}$ & $\begin{array}{c}0.0319 \\
(0.0313)\end{array}$ & $\begin{array}{l}-0.0160 \\
(0.0393)\end{array}$ & $\begin{array}{l}-0.0218 \\
(0.0474)\end{array}$ & $\begin{array}{l}-0.0433 \\
(0.0982)\end{array}$ \\
\hline $\begin{array}{l}\text { Experience } \\
\text { (difference) }\end{array}$ & $\begin{array}{c}-0.0591 * \\
(0.0163)\end{array}$ & $\begin{array}{l}-0.0588 * \\
(0.0191)\end{array}$ & $\begin{array}{l}-0.0645 * \\
(0.0176)\end{array}$ & $\begin{array}{c}-0.0785 * \\
(0.0358)\end{array}$ & $\begin{array}{l}-0.0376 \\
(0.0305)\end{array}$ & $\begin{array}{l}-0.0554 \dagger \\
(0.0309)\end{array}$ \\
\hline Experience Popularity & $\begin{array}{c}0.0078 \\
(0.0192)\end{array}$ & $\begin{array}{c}0.0008 \\
(0.0211)\end{array}$ & $\begin{array}{l}-0.0166 \\
(0.0244)\end{array}$ & $\begin{array}{l}-0.0023 \\
(0.0059)\end{array}$ & $\begin{array}{c}0.0007 \\
(0.0071)\end{array}$ & $\begin{array}{c}0.0139 \\
(0.0342)\end{array}$ \\
\hline
\end{tabular}


Determinants of Knowledge-sharing Networks in Primary Care

\begin{tabular}{|l|c|c|c|c|c|c|} 
Same association & 0.5752 & 0.1404 & 0.5325 & $2.4257 *$ & $2.0821 *$ & $2.4721 *$ \\
(Covariate Arc) & $(0.6581)$ & $(0.7980)$ & $(0.6518)$ & $(0.6742)$ & $(0.5964)$ & $(0.7839)$ \\
& $1.1678 *$ & $1.2311 *$ & $1.1880 *$ & 0.0587 & 0.1095 & 0.1378 \\
District & $(0.2662)$ & $(0.2776)$ & $(0.2825)$ & $(0.3945)$ & $(0.3749)$ & $(0.4337)$ \\
(matches) & 0.6057 & 0.1556 & 0.4611 & 0.2616 & 0.3111 & $0.5237 *$ \\
Taskforce & $(0.4156)$ & $(0.6402)$ & $(0.5412)$ & $(0.1939)$ & $(0.2127)$ & $(0.2610)$ \\
(Covariate Arc) & & & & & \\
Distance & $-0.0460 *$ & $-0.0411 *$ & $-0.0447 *$ & $-0.0791 *$ & $-0.0953 *$ & $-0.1331 *$ \\
(Covariate Arc) & $(0.0129)$ & $(0.0144)$ & $(0.0145)$ & $(0.0263)$ & $(0.0295)$ & $(0.0398)$ \\
\hline
\end{tabular}

Note: Standard errors are in parentheses. Significance levels: $*=p<0.01 ; \dagger=p<0.05$ 